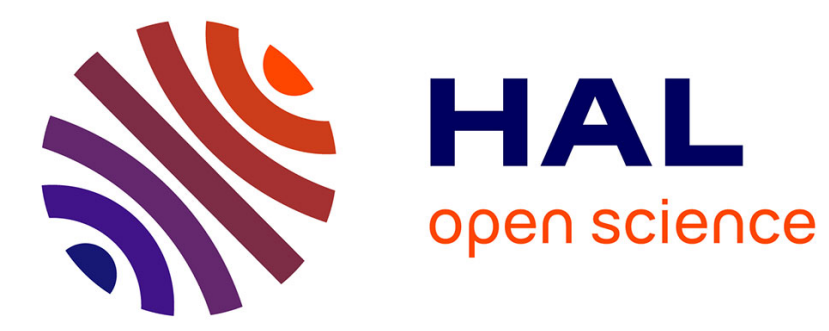

\title{
Probabilistic evaluation to improve design of impact-echo sources
}

Franck Schoefs, Odile Abraham

\section{To cite this version:}

Franck Schoefs, Odile Abraham. Probabilistic evaluation to improve design of impact-echo sources.

Transportation Research Record, 2012, 2313, pp.109-115. 10.3141/2313-12 . hal-00851314

\section{HAL Id: hal-00851314 \\ https://hal.science/hal-00851314}

Submitted on 13 Aug 2013

HAL is a multi-disciplinary open access archive for the deposit and dissemination of scientific research documents, whether they are published or not. The documents may come from teaching and research institutions in France or abroad, or from public or private research centers.
L'archive ouverte pluridisciplinaire HAL, est destinée au dépôt et à la diffusion de documents scientifiques de niveau recherche, publiés ou non, émanant des établissements d'enseignement et de recherche français ou étrangers, des laboratoires publics ou privés. 


\title{
Probabilistic Evaluation to Improve Design of Impact-Echo Sources
}

\author{
Franck Schoefs and Odile Abraham
}

The aim of the study reported in this paper was to provide rational aid tools to quantify the performance of nondestructive testing (NDT) tools. This study focused on the quantification of the performance of impactecho sources (steel balls of varied diameters), applied with a new, contactless robot, for duct void detection and thickness measurements in a reinforced concrete wall. Because of uncertainties during the testing, the data were analyzed in a probabilistic context, with the knowledge that on-site inspections were affected by uncertainties. The $\alpha \delta$ method was used in this regard, where the probabilities of detection and false alarm rates were used to build receiver operating characteristic curves. The methodology was applied to data measured on the same wall with two steel ball diameters: 0.16 and $0.125 \mathrm{~m}$. The quantity analyzed here was the impact-echo method (resonance) frequency. This methodology could be extended to other parameters of the impact-echo setup as well as to other NDT methods.

Preventive replacement of engineering structures results in high economic and environmental costs and thus heightens interest in the maintenance of these structures with efficient management plans. The challenge for owners is how to guarantee the operation and safety of aging structures, while reasonable costs and availability are ensured. Prestressed structures meet all of these conditions. Owners face existing structures with potential internal defects that are hard to detect and can affect safety. They base their maintenance decision schemes mainly on structural integrity assessment and consequence analysis. The major inputs come from information collected by inspections that employ nondestructive or destructive tools. Uncertainties and errors of measurement can lead to bad decisions but are rarely integrated into the decision process. Risk-based inspection (RBI) (1-8) provides the basic concepts to optimize the maintenance plans of existing structures and to ensure that their safety and availability are satisfactory over the service life of the structures. RBI depends on both reliability computations and probabilistic modeling of inspection results.

Reassessment of existing structures emphasizes the need for updated material properties with reliable techniques. In general, on-site inspections are necessary, and in some cases visual inspections are not sufficient. Nondestructive testing (NDT) tools are then required. Inspection of large structures within their natural envi-

F. Schoefs, Lunam Université, GeM, CNRS UMR 6183, 2 Rue de la Houssinière BP 92208, F-44322 Nantes CEDEX 3, France. O. Abraham, Lunam Université, IFSTTAR, MACS, CS4, F-44344 Bouguenais CEDEX, France. Corresponding author: O. Abraham, odile.abraham@ifsttar.fr. ronments takes into account human factors (e.g., access, tiredness, lack of experience), which means that conditions are far less ideal than they are in the laboratory. In this context, the cost of inspection can be prohibitive, and an accurate description of the on-site performance of NDT tools must be provided. When the conditions for inspection of existing structures are not ideal, it has become common practice to model their reliability in terms of probability of detection $(\mathrm{PoD})$, probability of false alarm (PFA), and receiver operating characteristic (ROC) curves $(9,10)$. These inputs are the main ones needed by owners of structures who hope to achieve inspection, maintenance, and repair plans through RBI methods. In this study, this general framework and associated tools were used to propose a methodology to quantify the pertinence of the NDT source within the context of the impact-echo method.

This paper reviews theoretical aspects of detection theory and probabilistic modeling of inspection results. It presents an experimental program carried out on a specific wall with a contactless robot and the impact-echo method. Finally, results obtained with two impact-echo sources are discussed in terms of PoD, PFA, and void detection capability. This approach complemented work published in the literature aimed at the qualification of the impact-echo method (11).

The methodology developed could be implemented to design optimal NDT setups and procedures for methods other than the impact-echo.

\section{PROBABILISTIC MODELING}

\section{PoD and PFA}

The most common concept that characterizes the performance of inspection tools is PoD. Let $a_{d}$ be the minimal defect size, called the detection threshold, under which it is assumed that no detection is possible. PoD is defined as

$\mathrm{PoD}=P\left(\hat{D} \geq a_{d}\right)$

where $\mathrm{P}()$ represents a probability measure, and $\hat{D}$ is the variable that represents the measured defect size $\hat{d}$ [response level of NDT tool (i.e., signal + noise)]. The real defect size (i.e., real signal without noise) is $D$.

If it is assumed that the probability density functions of noise and signal amplitude are known (e.g., after the empirical distribution is fitted), PoD and PFA have the following expressions:

$\mathrm{PoD}=\int_{a_{d}}^{+\infty} f_{\hat{D}}(\hat{d}) \partial \hat{d}$ 
$\mathrm{PFA}=\int_{a_{d}}^{+\infty} f_{\Lambda}(\eta) \partial \eta$

where $\eta$ equals noise and $f_{\hat{D}}$ and $f_{\Lambda}$ are probability density functions of signal + noise $\hat{D}$ (or measured defect) and noise $\Lambda$, respectively. Noise $\Lambda$ and signal $D$ were considered independent random variables.

Thus PoD is a function of the detection threshold, the measured defect size, and the noise, whereas PFA depends on the detection threshold and noise only (12). Noise depends on the decision chain (physical measurement decision on defect measurement transfer of information), the conditions of inspection (e.g., harsh environment, surface quality, electronic noise), and the complexity of testing procedures (e.g., accessibility, mounting of device).

Figure 1 illustrates the probability density function (PDF) and the area to be computed for the evaluation of PoD and PFA for a given detection threshold in the case in which signal + noise $\hat{D}$ and noise $\Lambda$ are normally distributed.

\section{ROC Curve}

The ROC curve links the PoD and the PFA. For a given detection threshold, the pair (PFA, PoD) defines NDT performance. This pair can be considered to comprise the coordinates of a point in $\mathrm{R}^{2}$ (square integrable space of real numbers) with axes that represent PFA and PoD. If $a_{d}$ takes values in the range ] $-\infty ;+\infty$ [, these points belong to a curve called ROC, which is a parametric curve with parameter $a_{d}$ and defined by Equations 2 and 3 .

The example of a ROC curve (ROC 3) plotted in Figure 2 was computed with the PDF presented in Figure 1, which corresponded to normal distributions.

The ROC curve is a fundamental characteristic of the NDT tool performance for a given defect size. The perfect tool is represented by a ROC curve reduced to a single point whose coordinates are (PFA, $\mathrm{PoD})=[0,1]$. A ROC curve represents an NDT tool performance that faces a given PDF of a defect or a defect range (9).

Figure 2 presents three theoretical ROC curves, and each one corresponds to a different NDT tool performance. The worst curve is ROC 1, which means that noise can be easily detected as a

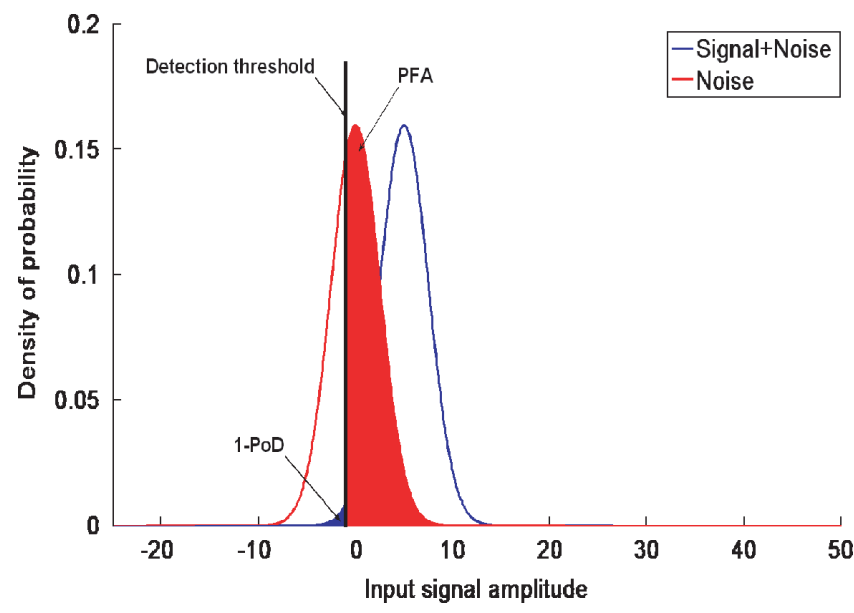

FIGURE 1 Illustration of PoD and PFA (signal + noise and noise normally distributed] for detection threshold $a_{d}$.

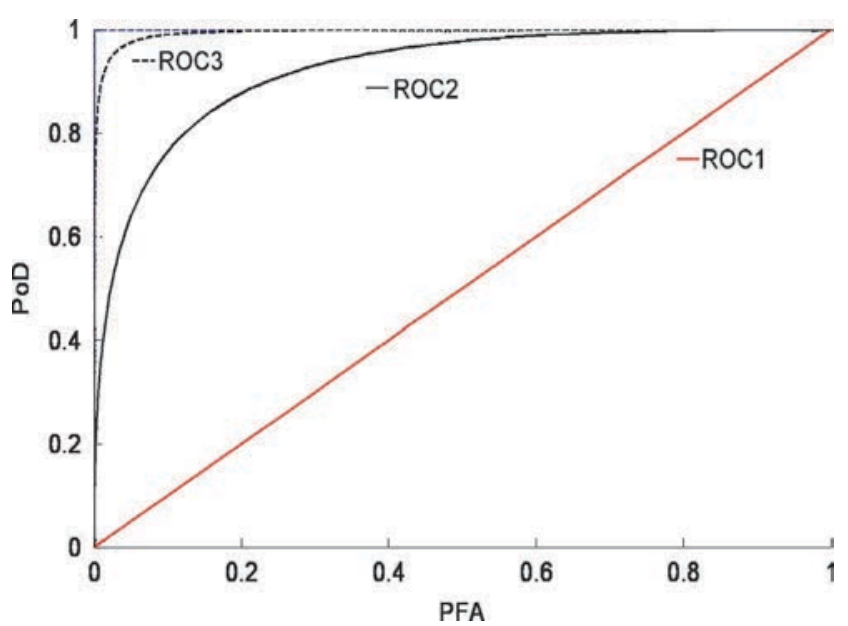

FIGURE 2 Example of ROC curves with several NDT performances.

defect even if nothing is to be detected. This finally leads to a high number of false alarms. As a result, overall performances are poor. In contrast, the best plotted ROC curve is ROC 3, which differs considerably from the previous curve. The probability of detection reaches values near 1 , with small PFAs for high values of PoD. Overall performances are good.

These ROC curves can be obtained through two techniques and the same defect range, one technique and two defect ranges, one technique with two settings and the same defect range, or one technique applied under various conditions (even if the testing procedure is rigorously followed during inspection). In the following paragraphs, two settings and the same defect are discussed.

A simple geometric characterization of ROC curves is the distance between the curve and the best performance point (BPP) of coordinates $(\mathrm{PFA}=0, \mathrm{PoD}=1)(13)$. By definition, the greater the distance, the worse the performance. The point on the ROC curve that corresponds to the shortest distance between BPP and the curve is called the performance point of the NDT tool (NDTBPP). This distance (Euclidean measure) thus can be considered a measure of performance. This paper defines a curve characterization with the polar coordinates of the NDT-BPP. The NDT-BPP polar coordinates are defined as follows:

- The radius $\delta_{\mathrm{NDT}}$ equals the performance index (NDT-PI) (distance between BPP and ROC curve) (12-14) and

- The $\alpha_{\mathrm{NDT}}$ is the angle between axis $(\mathrm{PFA}=0)$ and the line (BPP, NDT-BPP).

Barnouin et al. have shown that $\alpha_{\mathrm{NDT}}$ is essential to provide complete risk analysis, including consequence assessment after inspection (15). However, such an analysis was beyond the scope of the study reported here, and this parameter was not analyzed. Assessment of PoD and PFA with the knowledge of the detection threshold can be directly deduced from intercalibration of NDT tools from statistical analysis of inspection results (15, 16). In general, such projects are expensive. Consequently, it is sometimes necessary to choose another approach. Calculation of PFA and PoD thereby results from probabilistic modeling of the noise and signal + noise PDF $(12,14)$. Other authors (17) have suggested other concepts, such as the probability of false indica- 
tion. The main disadvantage is that PFA and the probability of no detection are mixed and that the size of the defect and the modeling of the noise are no more present.

\section{Statistical ROC Building}

Here the NDT tool was still under development and the detection threshold unknown. ROC curves were built from statistics and then the best detection threshold was deduced in terms of $\alpha_{\mathrm{NDT}}$ and $\delta_{\mathrm{NDT}}$. Thus PoD and PFA were computed from Equations 4 and 5 as follows (18):

$$
\begin{array}{ll}
\mathrm{PoD} \approx \frac{\operatorname{card}(A)}{n_{m}} & \text { with } A=\left\{i \in \mathfrak{I} ; \hat{f}_{p, i}<a_{d}\right\} \\
\mathrm{PFA} \approx \frac{\operatorname{card}(B)}{n_{m}} & \text { with } B=\left\{i \in \mathfrak{I} ; \eta_{j}<a_{d}\right\}
\end{array}
$$

where

$$
\begin{aligned}
\operatorname{card}(.) & =\text { cardinal of particular set, } \\
\mathfrak{I} & =\left\{1, \ldots, n_{m}\right\}, \text { and } \\
n_{m} & =\text { number of measurements. }
\end{aligned}
$$

Details are given in Schoefs et al. (19). The inversion of the sign for the inequality in the definition of $A$ and $B$, as compared with Equations 4 and 5, is due to the fact that PDFs are inverted. In Figure 1 , the noise PDF is on the left side and does not have a mean value of zero.

\section{TESTING PROCEDURE}

\section{Impact-Echo Method and Contactless Robot}

Impact-echo is a nondestructive resonance method developed more than 20 years ago in concrete slabs to measure thickness and to detect defaults, such as voids or delimitations characterized by a change of mechanical impedance at the interface $(20$, 21 ). It is now clearly established in slab (here wall) that the underlying physics of impact-echo consist of a resonance phenomenon associated with the zero group velocity frequency of the first symmetric Lamb mode $(22,23)$. Thus it appears that the thickness resonance frequency depends on the local stiffness of the wall. The wall thickness resonance frequency $f_{p}$ is related to the compression wave velocity $V_{P}$ and to the thickness $e$ with the following relation:

$f_{p}=\beta \frac{V_{P}}{2 e}$

where $\beta$ is a shape factor function of the Poisson ratio $v$. Its value for $v=0.22$ is 0.95 .

Impact-echo also has been considered as a tool to detect voids in tendon ducts. In the presence of a void, the thickness resonance frequency is lowered in a significant way and appearance of a secondary pick, usually $f_{\text {void }}$, also is expected (20). The latter phenomenon is harder to observe and is not considered here. This study investigated the modification of the thickness resonance frequency of a reinforced concrete wall in which ducts of various fillings were embedded.
To carry out measurements, a robot was designed to generate and record impact-echo signals on a $1.5-\mathrm{m} \times 1.9-\mathrm{m}$ surface. The source consisted of the impact of a steel ball monitored by an electromagnet. This paper proposes a way to quantify the influence of the choice of the steel ball diameter. The receiver was a laser interferometer from Polythec PI, which made the robot original compared with the contact ones (24). The Bakelite wood form used during the casting of the wall ensured a flat surface, and no surface preparation was needed to record the impact-echo signals.

\section{Specificity of Full-Scale Wall and Ducts}

A reinforced concrete wall was designed to illustrate the influence of the wall inner structure on impact-echo signals, including tendon ducts with various fillings. The wall was $0.25 \mathrm{~m}$ thick, $1.9 \mathrm{~m}$ high, and $1.5 \mathrm{~m}$ long. The concrete (CEM $152.5 \mathrm{~N}$ ) had a compressive strength at 28 days equal to $33 \mathrm{MPa}$. Its composition is given in Table 1. On the upper part of the wall, some additional steel was added to ease its transport by a traveling crane. Additional steel elements were inserted in the lower part for the same purpose.

The wall was divided into two sections (left and right) and each side had four horizontal tendon ducts, designated by the letter "L" or " $\mathrm{R}$ " for left or right. The ducts were assigned a number from 1 to 4 , which depended on their position (Figure 3). The distance between the ducts was $0.346 \mathrm{~m}$. The two sections of one duct line were connected by tape.

Table 2 summarizes the information related to each duct. All the tendon ducts had an external diameter of $0.04 \mathrm{~m}$ and an internal diameter of $0.038 \mathrm{~m}$ and were made of steel strip sheaths, except for one of them (R3), which was a thick, steel pipe (wall thickness, $5 \mathrm{~mm}$ ). Unless specified otherwise, the grout was Superstresscem. One tendon duct was filled with epoxy (L3) to represent a filling with degraded mechanical characteristics. The ducts contained, centered in their middle, one steel cable, except for Ducts L4, R4, and R3.

The ducts were embedded in a wall that was not identical from top to bottom. Indeed as previously stated, the regions above the higher duct and below the lower one were more heavily armed by steel elements. Those regions were the stiffest and were referred to as highly reinforced concrete, whereas the space between the ducts was denoted as ordinary concrete.

\section{Testing Procedure and Quantity of Interest}

The impact point and the measurement point were positioned $0.015 \mathrm{~m}$ apart; they were aligned horizontally. The measurement

TABLE 1 Concrete Composition

\begin{tabular}{lc}
\hline Material & Weight $(\mathrm{kg})$ \\
\hline Sand $(0 / 4 \mathrm{~mm})$ & 810 \\
Granulates $(2 / 10 \mathrm{~mm})$ & 130 \\
Granulates $(11.2 / 22.4 \mathrm{~mm})$ & 870 \\
Cement (CEM 1 $52.5 \mathrm{~N})$ & 334 \\
Chateaufil (Mont-Gens sur Loire) filler & 48 \\
Adjuvant Viscocrete 3045 & 0.62 \\
Water & 182.5 \\
\hline
\end{tabular}




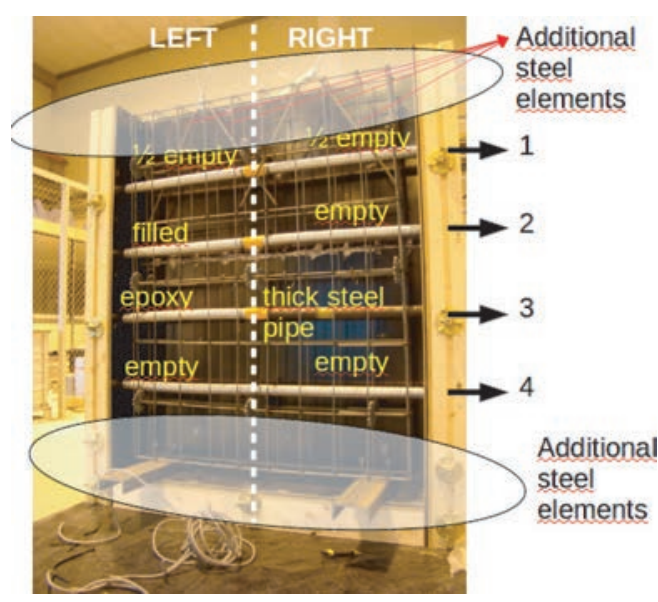

(a)

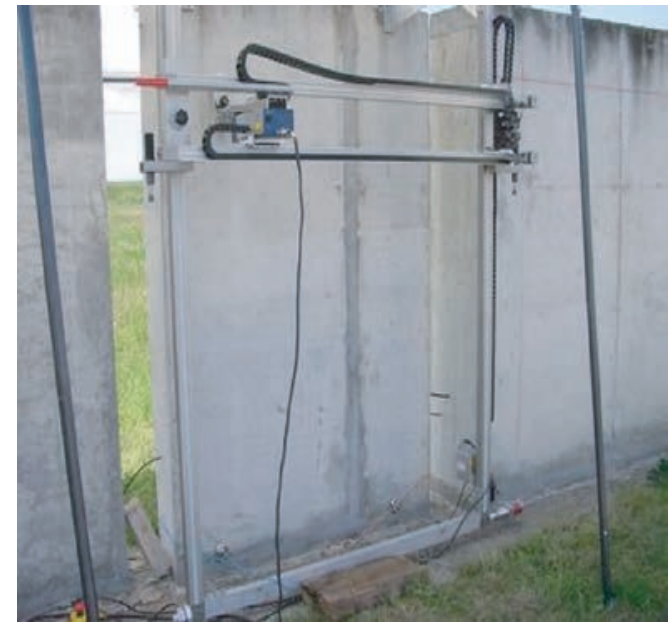

(b)

FIGURE 3 Concrete wall: $(a)$ wood form with four lines of duct and $(b)$ robot in use.

grid had a horizontal spacing of $0.02 \mathrm{~m}$ and a vertical one of $0.03 \mathrm{~m}$. The frequency that corresponded to the maximum amplitude was the thickness resonance frequency, called the peak frequency $f_{p}$, and was considered the impact-echo observable on each point of the grid. The resolution of the Fourier transform was equal to $\mathrm{df}=$ $244 \mathrm{~Hz}$. Within the investigated zone, meaningful peak frequencies varied between $6 \mathrm{kHz}$ and $9 \mathrm{kHz}\left(f_{p \text {,low }}\right.$ and $\left.f_{p \text {,up }}\right)$. An interval about the thickness resonance frequency $(7.7 \mathrm{kHz})$ with no pipe peak frequency outside the range $\left(f_{p \text {, low }} f_{p \text {,up }}\right)$ could be linked to measurement perturbations, such as surface disorder (typically air bubbles at the surface), which led to a bad signal with the laser interferometer. Signals deemed insufficient were removed from the database and not considered in the analysis.

The quantity selected for void detection was the peak frequency $f_{p}$ because it was linked to the wall section stiffness. The methodology obviously could be extended to other quantities of interest. Figure 4 presents the measurements obtained with steel balls with diameters of $0.016 \mathrm{~m}$ and $0.0125 \mathrm{~m}$; horizontal black lines indicate the limits of the tendons. The less stiff section (eventually the result of a void) led to low peak frequencies, whereas the high-stiffness section, especially at the top of the wall (with more rebars), led to high peak frequencies. Clearly, it was easier to detect a defect (i.e., void) in a stiff region. Thus the peak frequency of the region outside the duct area was called "noise."

\section{TABLE 2 Description of Tendon in Concrete Wall}

\begin{tabular}{lll}
\hline & Tendon Duct & \\
Nuct & Left (L) & Right (R) \\
\cline { 2 - 3 } 1 & $\begin{array}{c}\text { Half-empty (horizontal filling } \\
\text { with Superstresscem) }\end{array}$ & $\begin{array}{c}\text { Half-empty (vertical filling } \\
\text { with Superstresscem) }\end{array}$ \\
2 & $\begin{array}{l}\text { Fully filled with Superstresscem } \\
\text { Filled with epoxy }\end{array}$ & $\begin{array}{c}\text { Empty } \\
\text { Thick empty steel pipe, } \\
\text { no cable }\end{array}$ \\
4 & Empty, no cable & Empty, no cable \\
\hline
\end{tabular}

\section{RESULTS AND ANALYSIS}

\section{Pretreatment of Data}

First, from the original, all data were removed outside the interval $\left(f_{p \text {, low }}, f_{p \text {,up }}\right)$, as were the data near the horizontal frontier between concrete and duct (two lines of measurements), at the lower part of the wall, and at the end of the duct and between two aligned ducts in which a void in connection occurred.

Figure 5 shows mean peak frequencies (steel ball, $0.16 \mathrm{~m}$ ) plotted along the horizontal axis for the data collected for the ordinary concrete, the highly reinforced concrete, the left and the right parts of the ducts (Duct 1). This posttreatment is "trajectories in each area" in Figure 5. As the figure shows, the frequencies between concrete and ducts were easily distinguished. Moreover, the ends of the ducts and the connections between ducts (Figure 5) showed edge effects. These effects were linked to the fact that the peak frequency was sensitive to the average stiffness around the measurement point affected by edges and surrounding average stiffness.

\section{ROC and $\delta$ Computation}

Through knowledge of the distribution of the measurements in each zone, the couple (PoD, PFA) was deduced at each detection threshold $a_{d}$.

Figure 6 plots the eight ROC curves obtained for ducts when the noise was from ordinary concrete and with the steel ball $0.016 \mathrm{~m}$ in diameter. The shape of the curves varied, and one of them (Duct $3 R$ ) was in the part of the NDT tool rejection in the (PFA; PoD) graph: PFA > PoD. In that case (thick steel, empty duct) the method had less chance to detect a void than in the surrounding thickness resonance frequency because of the stiffness of the thick steel pipe. What mattered was the stiffness of the section rather than the presence or absence of a void. Thus detection of a void should be carried out carefully with information about inner reinforcements and concern about the duct stiffness properties. Comparison of peak frequencies along the duct itself is preferable. Scanners such as the one presented here or elsewhere (25) are useful because they produce two-dimensional maps. 


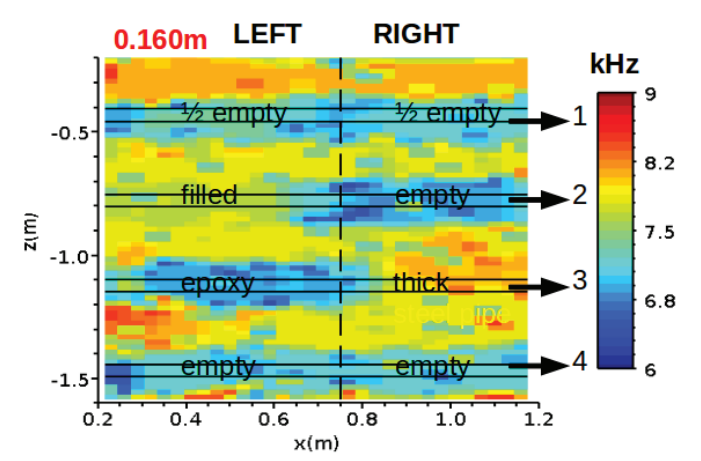

(a)

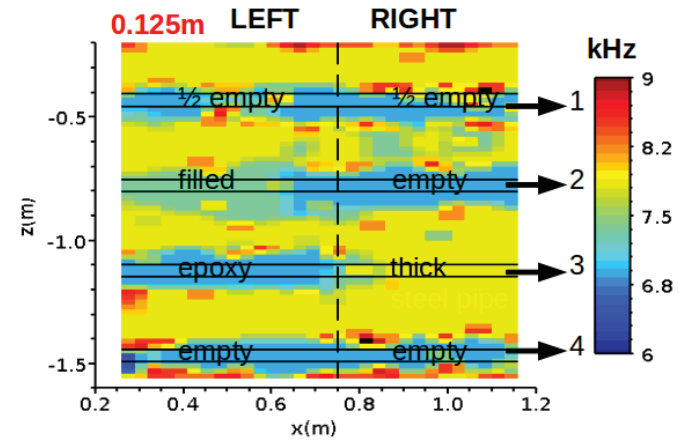

(b)

FIGURE 4 Peak frequency for two diameters: (a) $0.016 \mathrm{~m}$ and $(b) 0.0125 \mathrm{~m}$.

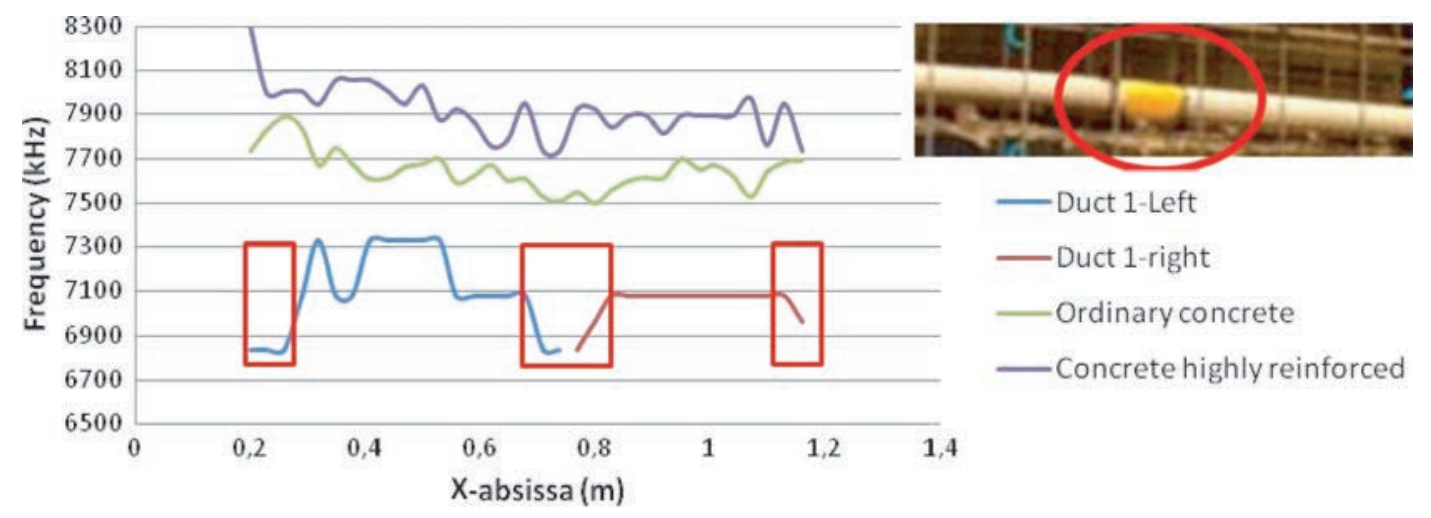

FIGURE 5 Trajectories of mean frequency for Duct 1.

In a previous study (19) $\delta_{\mathrm{NDT}}$ was computed for each of the 14 ROC curves, and it was shown that the precision of the $\delta_{\mathrm{NDT}}$ measure was about 0.015 . As expected, the higher the stiffness of the duct, the higher the peak frequency, and void detection capability was most difficult when the background considered was the concrete outside the duct area. The detection capability was more difficult when the duct was half-filled (void at the upper side) with Superstresscem grout (1L) and the duct was filled with epoxy (3L). It was in phase with the stiffness of the material inside the duct. Finally,

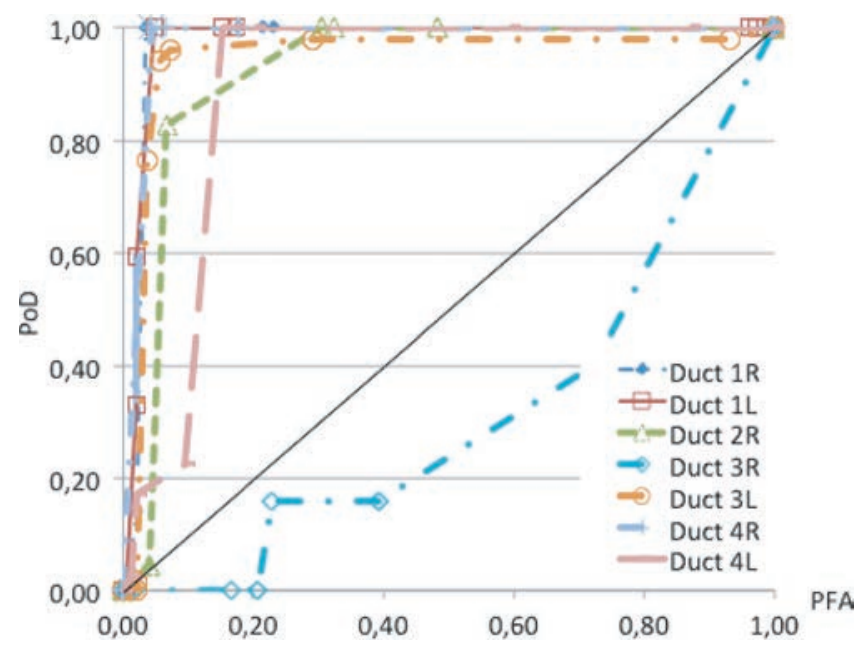

FIGURE 6 ROC curves for ducts in ordinary concrete. the detection of the void with a half-vertically filled duct (1R), or of an empty duct, with ( $2 \mathrm{R})$ or without tendon (4L, $4 \mathrm{R})$, led to the same detection capability with the present protocol, and they could not be distinguished in the study. Those results were obtained with one measurement setup. The following section describes how the probabilistic methodology could be used to quantify the improvement or deterioration of the impact-echo performance when one parameter of the setup is modified.

\section{Impact-Echo Method with Steel Ball Diameters}

The influence of the source diameter on the results was considered. Impact-echo, two-dimensional scanning was carried out on the same wall with exactly the same settings except that the diameter of the steel ball used as a source decreased from $0.16 \mathrm{~m}$ to $0.125 \mathrm{~m}$ (Figure 5). Figure 7 shows that the void detection capability increased

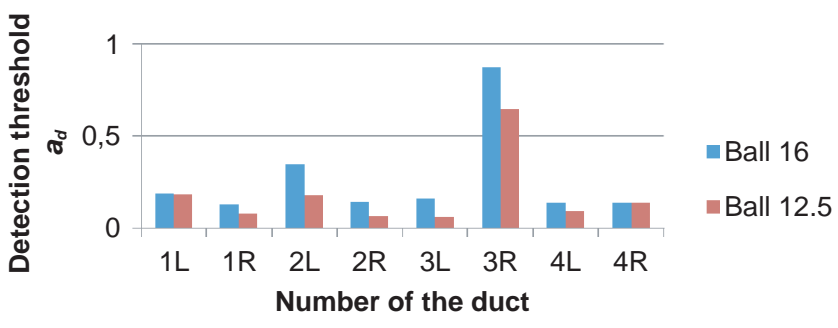

FIGURE 7 Comparison of $a_{d}$ between tests: ball with diameter of $0.0125 \mathrm{~m}$ and $0.016 \mathrm{~m}$ in ordinary concrete. 
TABLE 3 Values of PoD and PFA for Detection Threshold of $7.1 \mathrm{~Hz}$ and Value for Best Threshold $a_{d}$ for Ducts $1 \mathrm{R}$ and $2 \mathrm{R}$, and $4 \mathrm{~L}$ and $4 \mathrm{R}$

\begin{tabular}{lccccccc}
\hline Duct & $\mathrm{PoD}_{16}$ & $\mathrm{PFA}_{16}$ & $\mathrm{PoD}_{12,5}$ & $\mathrm{PFA}_{12,5}$ & $a_{d}(\mathrm{kHz})$ & $\mathrm{PoD}_{12,5}$ & $\mathrm{PFA}_{12,5}$ \\
\hline $1 \mathrm{R}$ & 1 & 0.02 & 1 & 0.161 & 7.3 & 1 & 0.161 \\
$\mathrm{R}$ & 1 & 0.3 & 1 & 0.161 & 6.9 & 1 & 0.068 \\
$4 \mathrm{~L}$ & 1 & 0.04 & 0.933 & 0.03 & 7.4 & 1 & 0.03 \\
$4 \mathrm{R}$ & 1 & 0.15 & 0.883 & 0.028 & 7.4 & 0.953 & 0.04 \\
\hline
\end{tabular}

TABLE 4 Values of PoD and PFA for Detection Threshold of $7.1 \mathrm{~Hz}$ and Value for Best Threshold $a_{d}$ for Ducts $1 \mathrm{~L}$ and $3 \mathrm{~L}$ and $3 \mathrm{R}$

\begin{tabular}{llllllll}
\hline Duct & $\mathrm{PoD}_{16}$ & $\mathrm{PFA}_{16}$ & $\mathrm{PoD}_{12,5}$ & $\mathrm{PFA}_{12,5}$ & $a_{d}(\mathrm{kHz})$ & $\mathrm{PoD}_{12,5}$ & $\mathrm{PFA}_{12,5}$ \\
\hline $1 \mathrm{~L}$ & 0.59 & 0.02 & 0.754 & 0 & 7.4 & 1 & 0.02 \\
$3 \mathrm{~L}$ & 0.94 & 0.06 & 1 & 0.062 & 6.9 & 1 & 0.062 \\
$3 \mathrm{R}$ & 0 & 0.21 & 0.041 & 0.067 & 7.4 & 0.236 & 0.280 \\
\hline
\end{tabular}

when a ball with a diameter of $0.0125 \mathrm{~m}$ was used. However, some differences were not significant because they stayed in the range of uncertainty for distance evaluation (0.015). In terms of PoD-PFA, it was shown (19) that the detection threshold was $7.1 \mathrm{kHz}$ for a ball that had a diameter of $0.16 \mathrm{~m}$. The threshold varied from 6.9 to $7.4 \mathrm{kHz}$ for a ball with a diameter of $0.125 \mathrm{~m}$ and depended on the case.

When $7.1 \mathrm{kHz}$ was selected in any case, except for Duct 1R, PoD increased and PFA decreased when a steel ball with a $0.0125-\mathrm{m}$ diameter was used; the results were equivalent for Duct 4R (Table 3, left). In the right part of the tables, the detection threshold was adjusted for each case, which of course improved the results. However, this practice could only be used on site if the typology of void was known (e.g., from forensic engineering). If not, results could be affected (e.g., with $a_{d}=6.9 \mathrm{kHz}$ for voids in Configuration 1L, PoD decreased from 1 to 0.754 ).

Table 4 shows the same information for Duct 3L, which was easy to detect because its filling mimicked a degraded material. Duct 1L was more easily detected with a steel ball that had a diameter of $0.0125 \mathrm{~m}$. Duct 3R remained undetected.

The methodology presented in this paper had its basis in the signal analysis of impact-echo measurements (i.e., peak frequency). This methodology was shown to be efficient if a calibration was made (i.e., the underlying state was known). However, such a calibration was not mandatory if the exact position of ducts on a real structure was known. Thus the noise could be characterized, and the great amount of data collected by the robot made it possible to plot ROC curves. The bad ROC curve provided by full ducts then was interesting to set aside this case.

\section{Practical Applications}

At present, the use of ROC curves is not typical in most NDT applications in civil engineering. In this study, it was thought of as a possible way to quantify the improvement of NDT equipment or to evaluate a new system through its comparison with old ones. Thus it was seen as a way to introduce rationalization in a domain in which commercial offerings sometimes were confusing. Another application domain was that of decision-aid tools in cases in which probalization of errors must be taken into account (e.g., probability of the absence of defect, with the knowledge that a detection leads to unnecessary repair). There was a relationship between this probability and PoD and PFA. If an on-site condition should differ from the laboratory conditions described in this paper, calibration should be made with the appropriate cover thickness and concrete.

\section{CONCLUSION}

This paper has its basis in an original database of about 2,000 values of peak frequency measured on a wall with a contactless robot and the impact-echo method. A statistical analysis of results is presented, as well as estimates of PoD and of PFA under varied duct conditions. The $\alpha \delta$ method is suggested as a rational aid-tool to quantify the detection capability of the technique when a setup parameter is changed. It is shown to be suitable to distinguish cases in which the duct is filled and cases with a void, to quantify the detection capability, and to rank protocols of the impact-echo method.

\section{ACKNOWLEDGMENTS}

The authors thank John Popovics for his helpful remarks and their fruitful discussions with him. The authors also thank the French National Agency for Research and Electricité de France for funding part of this research within the project ACTENA (Auscultation des Cables Tendus Non-Accessibles). The authors acknowledge Louis-Marie Cottineau, Fabrice Blaineau, Alain Grosseau, and Michel Valade for the design and realization of the robot. The wall was built under the supervision of Bernard Guieysse, and the tendon duct preparation was carried out by Jean-Francois David. Thibault Delacourt, Daniel Lerat, and Guillaume Levillain also are thanked.

\section{REFERENCES}

1. Faber, M.H. Risk Based Inspection: The Framework. Structural Engineering International, Vol. 12, No. 3, 2002, pp. 186-194.

2. Breysse, D., S. M. Elachachi, E. Sheils, F. Schoefs, and A. O'Connor. Life Cycle Cost Analysis of Ageing Structural Components Based on 
Nondestructive Condition Assessment. Australian Journal of Structural Engineering, Vol. 9, No. 1, 2009, pp. 55-66.

3. Sheils, E., A. O'Connor, D. Breysse, F. Schoefs, and S. Yotte. Development of a Two-Stage Inspection Process for the Assessment of Deteriorating Bridge Structures. Reliability Engineering and System Safety, Vol. 95, No. 3, 2010, pp. 182-194.

4. Schoefs, F. Risk Analysis of Structures in Presence of Stochastic Fields of Deterioration: Coupling of Inspection and Structural Reliability. Australian Journal of Structural Engineering, Vol. 9, No. 1, 2009, pp. 67-78.

5. Faber, M. H., D. Straub, and J. Goyet. Unified Approach to Risk Based Inspection Planning for Offshore Production Facilities. Journal of Offshore Mechanics and Arctic Engineering, Vol. 125, No. 2, 2003, pp. 126-131.

6. Goyet, J., D. Straub, and M. H. Faber. Risk Based Inspection Planning for Offshore Installations. Structural Engineering International, Vol. 12, No. 3, 2002, pp. 200-208.

7. Straub, D., and M. H. Faber. Risk Based Inspection Planning for Structural Systems. Structural Safety, Vol. 27, No. 4, 2005, pp. 335-355.

8. Straub, D., and M.H. Faber. Computational Aspects of Risk Based Inspection Planning. Computer-Aided Civil and Infrastructure Engineering, Vol. 21, No. 3, 2006, pp. 179-192.

9. Rouhan, A., and F. Schoefs. Probabilistic Modelling of Inspections Results for Offshore Structures. Structural Safety, Vol. 25, No. 4, 2003, pp. 379-399.

10. Pakrashi, V., F. Schoefs, J. B. Memet, and A. O'Connor. ROC Dependent Event Isolation Method for Image Processing Based Assessment of Corroded Harbour Structures. Structure and Infrastructure Engineering: Maintenance, Management, Life-Cycle Design and Performance, Vol. 6, No. 3, 2010, pp. 365-378.

11. Martin, J., M. S. A. Hardy, A. S. Usmani, and M. C. Forde. Accuracy of NDE in Bridge Assessment. Engineering Structures, Vol. 20, No. 11, 1998, pp. 979-984.

12. Schoefs, F., A. Clément, and A. Nouy. Assessment of Spatially Dependent ROC Curves for Inspection of Random Fields of Defects. Structural Safety, Vol. 31, No. 5, 2009, pp. 409-419.

13. Schoefs, F., and A. Clément. Multiple Inspection Modeling for Decision Making and Management of Jacket Off-Shore Platforms: Effect of False Alarms. First International Forum on Engineering Decision Making, Stoos, Switzerland, 2004.

14. Schoefs, F., A. Clément, J. Boéro, and B. Capra. The $\alpha \delta$ Method for Modeling Expert Judgment and Combination of NDT Tools in RBI
Context: Application to Marine Structures. Structure and Infrastructure Engineering: Maintenance, Management, Life-Cycle Design and Performance, Vol. 8, No. 6, 2012, pp. 531-543.

15. Barnouin, B., L. Lemoine, W.D. Dover, J.R. Rudlin, S. Fabbri, G. Rebourget, D. Topp, R. Kare, and D. Sangouar. Underwater Inspection Reliability Trials for Offshore Structures. Proc., 12th International Conference on Offshore Mechanics and Arctic Engineering, Vol. 2, 1993, pp. 883-890.

16. Rudlin, J. R. Reliability of Inspection for Fatigue Cracks in Offshore Structures. Institution of Electrical Engineers, London, 1996, pp. 6/1-6/3.

17. Straub, D., and M.H. Faber. Modelling Dependency in Inspection Performance. Proc., Application of Statistics and Probability in Civil Engineerings. San Francisco, Calif., 2003, pp. 1123-1130.

18. Baroth, J., F. Schoefs, and D. Breysse (eds.). Construction Reliability. Wiley-ISTE, Hoboken, N.J., forthcoming.

19. Schoefs, F., O. Abraham, and J. Popovics. Quantitative Evaluation of NDT Method Performance: Application Example Based on Contactless Impact Echo Measurements for Void Detection in Tendon Duct. Journal of Construction and Building Materials, forthcoming.

20. Sansalone, M. J., and W. B. Streett. Impact Echo: Nondestructive Evaluation of Concrete and Masonry. Bullbrier Press, Ithaca, N.Y., 1997.

21. Abraham, O., and P.H. Côte. Impact-Echo Thickness Frequency Profile for the Detection of Voids in Tendon Duct. ACI Structural Journal, Vol. 99, No. 3, 2002, pp. 239-247.

22. Gibson, A., and J.S. Popovics. Lamb Wave Basis for Impact-Echo Method Analysis. Journal of Engineering Mechanics, Vol. 131, No. 4 2005, pp. 438-443.

23. Prada, C., D. Clorennec, and D. Royer. Power Law Decay of Zero-Group Velocity Lamb Modes. Wave Motion, Vol. 45, No. 6, 2008, pp. 723-728.

24. Taffe, A., T. Kind, M. Stoppel, and H. Wiggenhauser. OSSCAR: Development of an On-Site SCAnneR for Automated Nondestructive Bridge Testing. In Concrete Repair, Rehabilitation and Retrofitting II (M. G Alexander, H.-D. Beushausen, F. Dehn, and P. Moyo, eds.), Taylor \& Francis Group, London, 2009, pp. 541-545.

25. Algernon, D., B. Grafe, F. Mielentz, B. Kolher, and F. Schubert. Imaging of Elastic Wave Propagation in Concrete Using Scanning Techniques: Application for Impact-Echo and Ultrasonic Echo Methods. Journal of Nondestructive Evaluation, Vol. 27, No. 1-3, 2008, pp. 83-97. 